\title{
Using the entropy of cover method in the analysis of investment risks
}

\author{
Vadim Kankhva, ${ }^{1, *}$ \\ ${ }^{1}$ Moscow State University of Civil Engineering, 129337, Yaroslavskoye shosse, 26, Moscow, Russia
}

\begin{abstract}
The purpose of this article is to expand knowledge about qualitative and quantitative criteria for assessing investment risks and the properties of investment processes from the point of view of presenting real dynamic processes of investment exchange in the target information space. The method of the entropy of cover is the main method that is considered in the article when analyzing and managing risks. The paper suggests the grouping of the main risks in accordance with classification criteria and management levels, since the ranking of risks is associated with certain types of investments. Also, the article considers the main provisions using the information measure - the entropy of cover, which allow leading to the search for optimal information management of investment risk. The proposed methodology has sufficient flexibility, and it can be used to solve a variety of problems in the analysis of investment projects. It does not require a global restructuring of the financial management system, allows attracting resources already available and is an effective tool in the struggle against uncertainty.
\end{abstract}

\section{Introduction}

In order to ensure economic stability and security of the activities of construction companies, risk management is to be systemic. Any risk management system, which should be considered as a set of many different elements, is aimed at quantitative and qualitative risk reduction. Stable development of an enterprise is adversely affected by the fact that the adoption of strategic decisions often takes place in the context of an already accomplished risky event.

Investment risk management is a special area of activity, requiring a broader and more informal analysis. This is due to the fact that Russian investors have to identify and assess almost all the risks associated with investment in construction. In the case of objective identification of risks connected with investment in the construction sector, it becomes possible to more accurately determine the appropriate benefits. The foregoing will improve the quality of the loan portfolio of investors, reduce the transaction value and will contribute to a more active development of the investment activities in Russia [1]. To do this, investors need to be able to correctly assess and manage investment risks.

\footnotetext{
*Corresponding author: vskanhva@ mail.ru
} 


\section{Materials and Methods}

In this study, it is proposed to use the entropy of cover method as a method of risk management, which helps to form the target functional for each task to search for optimal information management of the investment risks.

Due to the fact that investing in construction projects is associated with a risk of not receiving the expected effects, businesses have to undertake bold and non-trivial actions, which, in turn, increase the risk. Hence, there is a need to analyze, evaluate and manage risks, in order to identify opportunities to return investments and make a profit [2].

The existing groupings of risks in most cases have shortcomings associated with the impossibility of their effective and unambiguous introduction into the organizational structure of management of a construction enterprise. Thus, the classification of risks must have integrity, aggregation, openness, and to be inherent [3].

The generalized classification of risks will have the following form (Figure 1). The main classification feature in this case will be the grouping of risks by the management levels in the enterprise.

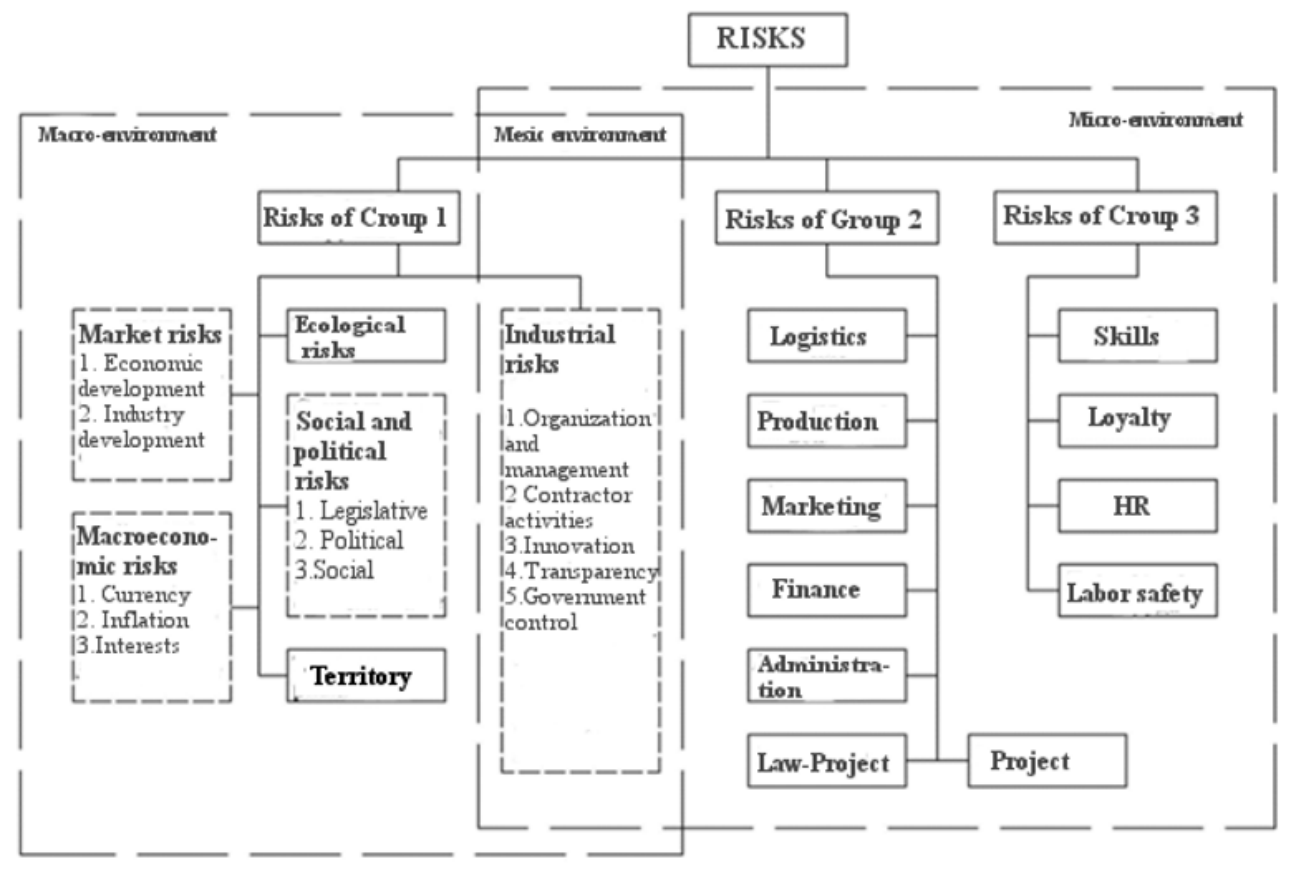

Fig. 1. The generalized classification of risks.

Classification of investments based on the level of risk ranking is necessary for the analysis of investment risks, since their different levels are connected with the specific type of investment. Classification of the main types of investment, depending on the level of risk is presented on the Figure 2 [4]. 




Fig. 2 Classification of investments

The mathematical formulation of the above provisions with the use of an information measure, that is, the entropy of cover allows leading to the search for the optimal information management of investment risk $[6,7,16]$.

\section{Results}

The entropy of cover determines the degree of correspondence of the system's tactical and technical characteristics to their required values through the relative cover logarithm by bringing many real technical parameters by the set of required parameters to the norm. form:

In general, in the vector case of the degree of correspondence, the cover has the following

$$
P_{\mathrm{p}}=\left\|C_{D p} D_{T} \cup D_{T}\right\|_{\mathrm{p}} /\left\|D_{T}\right\|_{\Pi}
$$

where: $C_{D p}$ is the operation of addition to the set of real technical indicators $D_{p}, D_{t}$ is the set of required technical indicators, \|\|$_{p}$ is the reduction operation to the norm.

As a reduction operation to the norm, the first, the second norm or the exponent from these quantities can be used. For vectors $r$, which characterize the general state of the control system object, the norm or this reduction has the following meaning: 


$$
\left\{\begin{array}{l}
\left\|\left\{\boldsymbol{r}_{i}\right\}\right\|=\left(\sum_{i=1}^{m}\left(r_{i}\right)^{2}\right)^{1 / 2} \\
\left\|\left\{\boldsymbol{r}_{i}\right\}\right\|_{\Pi}=\exp \left\{\sum_{i=1}^{m}\left|r_{i}\right|\right\}
\end{array}\right.
$$

To determine the distance between vectors, we use the following expression of the reduction to the norm:

$$
\left\{\begin{array}{l}
\left\|r_{k}-r_{l}\right\|=\left(\sum_{i=1}^{m}\left(r_{i k}-r_{i l}\right)^{2}\right)^{1 / 2} \\
\left\|r_{k}-r_{l}\right\|_{\Pi}=\exp \left\{\sum_{i=1}^{m}\left|r_{i k}-r_{i l}\right|\right\}
\end{array}\right.
$$

General view of the entropy of cover:

$$
H_{\text {п }}\left(D_{p}\right)=k \log \left\|C_{D p} D_{T} \cup D_{T}\right\|_{\mathrm{p}} /\left\|D_{T}\right\|_{\text {п }}
$$

The coefficient $\mathrm{k}$ determines the units of measurement of the entropy of cover, similar to the case of the Shannon entropy. For the entropy of cover, the traditional entropy units with the index "p" are used.

Cover information is a value equal to the difference of the entropy of cover at the initial moment of time and entropy of cover at the current time, so the cover information determines the degree of the project development at the current stage of the project management system $[8,12]$ :

$$
I_{\mathrm{p}}=\boldsymbol{H}_{\mathrm{p}}\left(\boldsymbol{D}_{0}\right)-\boldsymbol{H}_{\mathrm{p}}\left(\boldsymbol{D}_{t}\right)
$$

The information space of relations includes the elements of the expression of the target functional. In this case, the entropy of cover should decrease in the limit to zero, with the positive development of the process. The general view of the target functional is the following:

$$
F=T\left(H_{H}\left(D, t_{H}\right), H_{K}\left(D, t_{K}\right)\right)+\int_{T_{H}}^{T_{K}} J(u(R, t), h(D, t)) d t \rightarrow \min u
$$

where $T(\cdot)$ is the of functional terminants, $H_{H}(\cdot)$ is the initial entropy of cover, $H_{K}(\cdot)$ is the final entropy of cover, $\mathrm{D}$ is the vector of the generalized technical indicators of the company, $\mathrm{T}_{\mathrm{H}}, \mathrm{T}_{\mathrm{K}}$ is the initial and current time, $\mathrm{J}(\cdot)$ - integrand of the functional, $\mathrm{u}(\cdot)$ is the resource management function, $\mathrm{R}(\cdot)$ is the resource vector, $\mathrm{h}(\cdot)$ is the current entropy of cover, which is defined as the entropy of cover in an infinitesimal increment:

$$
\begin{gathered}
h(t)=\frac{d H(t)}{d t}=\lim _{\Delta t \rightarrow 0} \frac{H(t+\Delta t)-H(t)}{\Delta t}= \\
=\lim _{\Delta t \rightarrow 0}\left[/ \log \left(\left\|C_{D p} D_{T}(t+\Delta t) \cup D_{T}(t+\Delta t)\right\| /\left\|D_{T}(t+\Delta t)\right\|\right)\right. \\
\left.-/ \log \left(\left\|C_{D p} D_{T}(t) \cup D_{T}(t)\right\| /\left\|D_{T}(t)\right\|\right)\right] / \Delta t
\end{gathered}
$$

From the above formula it is clear that unlike the Shannon differential entropy, the entropy of cover has a correct definition in the differential form.

Terminant depends on the entropy of cover of the project at the beginning and at the final time part of the project process, so it has the form:

$$
T\left(H_{H}\left(D, t_{H}\right), H_{K}\left(D, t_{K}\right)\right)=H_{K}\left(D, t_{H}\right)-H_{H}\left(D, t_{K}\right)=-I_{\mathrm{pf}}
$$

where: $I_{p f}$ is the final cover information.

The integrand depends on the current entropy of cover and the control function being developed with respect to the resources of the project: 


$$
J(u(R, t), h(D, t))=u^{t}(D, t) V h(D, t)
$$

where: $\mathrm{V}$ is the matrix of the effects of the components of the vector $\mathrm{u}(\mathrm{D}, \mathrm{t})$ on the vector $\mathrm{h}$ $(\mathrm{D}, \mathrm{t})$, and the dimension of the matrix is $\mathrm{n}_{\mathrm{u}} \times \mathrm{n}_{\mathrm{h}}$. The elements of the matrix $\left\{\mathrm{v}_{\mathrm{k}}\right\}$ are the a priori adjustable coefficients $\left\{\alpha_{\mathrm{k} 1}\right\}$ for the corresponding positions of the elements $\left\{\mathrm{u}_{\mathrm{k} 1}\right\}$ in the differential equations of state $[9,12]$. The equations of state describe the dynamics of the vector of state in the subject (resource) area of the relationship.

The optimal use of available resources is the main requirement for the control function and consists in the need to maximize the current entropy of cover.

Limitations on the ability to use resources for the elements [10 - 12] of the project management system:

$$
F_{i} \leq H_{\max i}
$$

The form of the constraint equations looks like the form of the target functional in accordance with a single approach to the description of the functioning of all elements of the project management system:

$$
F_{i}=T_{i}\left(H_{H i}^{0}\left(R, t_{H}\right), H_{K i}^{0}\left(R, t_{K}\right)\right)+\int_{T_{H}}^{T_{k}} J_{i}\left(u_{i}(R, t), h_{i}^{0}(R, t)\right) d t
$$

However, in connection with possible changes of resources both in the direction of increasing and decreasing, the concept of the entropy of cover expands, for which the generalized entropy of cover $\mathrm{H}^{\mathrm{o}} \mathrm{i}(\mathrm{R}, \mathrm{t})$ and the current generalized entropy of cover $\mathrm{h}_{\mathrm{i}}^{\mathrm{i}}(\mathrm{R}, \mathrm{t})$ are introduced. In this case, the cover element is:

$$
\boldsymbol{P}_{\mathrm{p}}^{\mathbf{0}}=\left\{\begin{array}{c}
\left\|\left[\boldsymbol{C}_{\boldsymbol{R}}\left(\boldsymbol{R}_{\mathrm{d}} \cap \boldsymbol{R}_{H}(\boldsymbol{t})\right)\right] \cup\left(\boldsymbol{R}_{\mathrm{d}} \cap \boldsymbol{R}_{H}(\boldsymbol{t})\right)\right\|_{\mathrm{p}} /\left\|\boldsymbol{R}_{\mathrm{d}} \cap \boldsymbol{R}_{H}(\boldsymbol{t})\right\|_{\mathrm{p}} \\
\left\|\boldsymbol{R}_{H}(\boldsymbol{t})\right\|_{\mathrm{p}} /\left(\left\|\boldsymbol{R}_{H}(\boldsymbol{t})\right\|_{1}-\boldsymbol{r}\left\|\boldsymbol{C}_{\boldsymbol{R}}\left(\boldsymbol{R}_{\mathrm{d}} \cap \boldsymbol{R}_{\boldsymbol{H}}(\boldsymbol{t})\right)\right\|_{1}\right)
\end{array}\right.
$$

where: $R_{d}$ is the set of real resources of the project management system element, $R_{n}(t)$ is the set of normative resources at the current stage of the life cycle of the project management system, $r$ is the priority coefficient of the project management system element, for which the relative entropy of cover is calculated, $r \in(0 ; 1)$.

If the available resources are smaller than the normative ones, the first component of the vector is equal to 1 and cannot form an element of cover. In the absence of available resources we have an undefined situation: zero, divided by zero. Therefore, for $R_{d}=\varnothing$ we will define the function on the first component of the vector by 1 .

The generalized entropy of cover has the following form:

$$
\boldsymbol{H}\left(\boldsymbol{P}_{\mathrm{op}}(t)\right)=\boldsymbol{k}\left[\log \boldsymbol{P}_{\mathrm{op} 1}(t)+\boldsymbol{i} \log \boldsymbol{P}_{\mathrm{op} 2}(t)\right]
$$

where: $\mathrm{i}$ is the imaginary unit.

At each stage of the project life cycle, the complex values of the generalized entropy of cover determine the degree to which the resources of the system element correspond to the normative values. The existing part corresponds to an excess of resources, imaginary - a shortage for other resources. The current situation allows taking into account the reaction of each element of the project management system to its participation in the process of resource exchange within the framework of this system [12].

The current generalized entropy of cover takes the form:

$$
h_{i}^{o}(R, t)=d H_{i}^{o}(R, t) / d t=\lim _{\Delta t \rightarrow 0}\left(H_{i}^{o}(R, t+\Delta t)-H_{i}^{o}(R, t) / \Delta t\right)
$$

The terminant $T_{i}\left(H_{H}\left(R, t_{H}\right), H_{K}\left(R, t_{K}\right)\right)$ for expression (11) takes the form: 


$$
T_{i}\left(H_{H}\left(D_{i}, t_{H}\right), H_{K i}\left(D_{i}, t_{K}\right)\right)=H_{K}^{O}\left(D_{i}, t_{H}\right)-H_{H i}^{O}\left(D, t_{K}\right)=-I_{p f i}
$$

The integrand $\mathrm{J}_{\mathrm{i}}\left(\mathrm{u}_{\mathrm{i}}\left(\mathrm{R}_{\mathrm{i}}, \mathrm{t}\right), \mathrm{h}^{\mathrm{o}}{ }_{\mathrm{i}}\left(\mathrm{R}_{\mathrm{i}}, \mathrm{t}\right)\right)$ for the expression (11) takes the form:

$$
J_{i}\left(u_{i}\left(R_{i}, t\right), h^{o}\left(R_{i}, t\right)\right)=u_{i}^{t}\left(R_{i}, t\right) V_{i} h_{i}^{o}\left(R_{i}, t\right)
$$

where: $V_{i}$ is the matrix of the effects of the components of the vector $u_{i}\left(R_{i}, t\right)$ on the vector $\mathrm{h}_{\mathrm{i}}^{\mathrm{o}}\left(\mathrm{R}_{\mathrm{i}}, \mathrm{t}\right)$, the dimension of the matrix $\mathrm{n}_{\mathrm{ui}} \times \mathrm{n}_{\mathrm{hi}}$. The elements of the matrix $\left\{\mathrm{v}_{\mathrm{kl}}\right\}$ are the elements $\left\{\alpha_{\mathrm{k} l}\right\}$ for the corresponding positions of the elements $\left\{u_{\mathrm{k} l}\right\}$.

Information processes that take place in the project management system will be defined as the current change in the entropy of cover (generalized entropy of cover) between the elements $i$ and $j$ of the project management system for the corresponding resources:

$$
I_{i j}^{m}(\Delta t)=H_{i j}\left(P_{i}^{o}\left(\left\{\alpha_{i j}\right\}, t+\Delta t\right)\right)-H_{i j}\left(P_{i}^{o}\left(\left\{\alpha_{i j}\right\}, t\right)\right)=-I_{j i}^{m}(\Delta t)
$$

where $\mathrm{P}_{\mathrm{i}}^{\mathrm{o}}\left(\left\{\alpha_{\mathrm{i} j}\right\}\right)$ is the shared generalized cover of the resource set of the $\mathrm{i}^{\text {th }}$ element in accordance with its resource costs for the $\mathrm{j}^{\text {th }}$ element, determined by the coefficient vector $\left\{\alpha_{\mathrm{ij}}\right\}$.

The quantitative change in the generalized differential entropy of cover over a certain period of time in the exchange of resources between the elements of the project management system is a generalized information flow of cover [12-15]. Thus, from the element $i$ to the element $\mathrm{j}$ it has the following meaning:

$$
I_{i j}^{O}(\Delta t)=\int_{\Delta t} h^{o}\left(R_{i \rightarrow j}(t)\right) d t
$$

\section{Discussions}

The article examined the issues of assessing the effectiveness of investment projects and investment risks, as a result of the study of which the developed methodology for assessing integrated risk covered all the facets of uncertainty and efficiency arising during the activities of the organization at the stage of the investment decision-making to a particular project.

\section{Conclusion}

The proposed methodology does not require a global restructuring of the financial management system. It allows attracting already available labor resources and is the effective tool in the struggle against uncertainty. In addition to the dry mathematical apparatus, it pays attention to expert estimates. In addition, it should be noted that this methodology has very good flexibility, and it can be used to solve a variety of tasks in the investment projects analysis. As the main parameters by which projects are compared, it is permissible to use any criteria, and in unlimited quantities.

\section{References}

1. V. V. Gluhov, I. V. Ilin, Lecture Notes in Computer Science, 8638, 509- 518 (2014)

2. A. K. Orlov, I. Y. Chubarkina, MATEC Web of Conferences, 106, 08015 (2017)

3. V. Kankhva Procedia Engineering, 165, 1300-1304 (2016)

4. R. S. Golov, V.V. Shilov, S. A. Silantiev, Paper presented at 2017 ASEE International Forum, Columbus, Ohio (2017) 
5. V. Murgul, Energy-Efficient features to upgrade attic slabs of historical buildings (case study of Saint-Petersburg), MATEC Web of Conferences, 73, 02012 (2016)

6. F. Aggogeri, A. Avanzini, A. Borboni, S. Pandini, International Journal of Automation Technology, 11(2), 311-321 (2017)

7. Y. V. Ragulina, A. V. Bogoviz, A. N. Alekseev, Advances in Intelligent Systems and Computing, 622, 568-573 (2018)

8. R. Brazauskas, J. Le-Rademacher, Computer Methods and Programs in Biomedicine, 135, 199-207 (2016)

9. I. Kardes, A. Ozturk, S.T. Cavusgil, E. Cavusgil, International Business Review, 22, 905-917 (2013)

10. N. I. Vatin, Y. G. Barabanshchikov, M. V. Komarinskiy, S. I. Smirnov, Magazine of Civil Engineering, 56 (4), 1-10, 66-67 (2015)

11. M. Lu, C. Cheung, H. Li, S. Hsu. Accident Analysis \& Prevention, 94, 8-17 (2016)

12. M. A. Gatilov. Monitoring of the technical condition of production facilities as information systems using entropy coverage (Moscow, 2010)

13. N. Y. Yaskova, Scientific Review, 9, 505-507 (2013)

14. N. Y. Yaskova, D. N. Silka, Business activity management in a mixed construction sector (MGSU, Moscow, 2013)

15. N. Ivanov, MATEC Web of Conferences, 86, 05004 (2016)

16. S. Haghani, Journal of Empirical Finance, 28, 291-320 (2014) 